\title{
Gestalt-terapia e Cuidado
}

\author{
Care and Gestalt-therapy
}

Terapia Gestalt y Cuidado

\author{
Patricia Valle de Albuquerque Lima* \\ Universidade Federal Fluminense - UFF, Rio das Ostras, Rio de Janeiro, Brasil
}

\begin{abstract}
RESUMO
O presente artigo pretende considerar o conceito de cuidado dentro das perspectivas filosóficas e teóricas da Gestalt-terapia, buscando refletir sobre sua aplicabilidade na clínica ampliada. A experiência da autora, enquanto professora universitária e supervisora de estágio em Gestalt-terapia, servirá como ponto de sustentação para a reflexão sobre o cuidado na clínica ampliada, dado o vínculo que a mesma construiu e mantêm com a rede pública de saúde e assistência social em uma cidade do norte fluminense, através da oferta de estágio em diversos dispositivos desta rede. Ao longo deste artigo, não se pretende propor modos específicos de cuidado, mas refletir sobre a visão de cuidado em Gestalt-terapia e das implicações da abordagem na atuação do gestalt-terapeuta. O nosso objetivo, portanto, não é apontar modos apropriados de cuidar em Gestalt-terapia, mas possibilitar um maior entendimento do que podemos considerar cuidado e se a visão de cuidado proposta é compatível com a atuação na clínica ampliada.
\end{abstract}

Palavras-chave: gestalt-terapia, cuidado, clínica ampliada.

\section{ABSTRACT}

This article intends to consider the concept of care within the philosophical and theoretical perspectives of Gestalt-therapy, seeking to reflect on its applicability in the expanded clinic. The author's experience as a university professor and internship supervisor in Gestalt-therapy, will serve as a point of support for reflection on the care in the expanded clinic, given the link it has built and maintains with the public health and social care network in a city north of the state of Rio de Janeiro, through the offer of internship in various practices of this network. Throughout this article, the intention is not to propose specific forms of care but to reflect on the vision of care in Gestalt-therapy and the implication of it in the gestalt-therapist. Our objective, therefore, is not to indicate suitable ways to provide care in Gestalt-therapy but enable a deeper understanding of what we can consider care and whether the proposed view of care is compatible with the performance in the expanded clinic.

Keywords: gestalt-therapy, care, expanded clinic.

\section{RESUMEN}

El presente artículo pretende considerar el concepto de cuidado dentro de las perspectivas filosóficas y teóricas de la terapia Gestalt, tratando de reflexionar sobre su aplicabilidad en la clínica ampliada. La experiencia de la 
autora, como professora universitaria y supervisora de pasantía dentro del enfoque de la terapia Gestalt, servirá de punto de apoyo para la reflexión sobre el cuidado em la clínica ampliada, dado el vínculo que construyó y mantiene com la red de salud pública y asistencia social en una ciudad del norte del estado de Rio de Janeiro, por medio de la oferta de pasantía en diversos dispositivos de esta red. A lo largo de este artículo, no se pretende proponer modos específicos de atención, sino reflexionar sobre la visión de la atención en la terapia Gestalt y sus implicaciones para el desempeño del terapeuta gestalt. Nuestro objetivo, por lo tanto, no es señalar modos de atención apropiados en la terapia Gestalt, sino permitir una mayor comprensión de lo que podemos considerar atención y si la visión propuesta de la atención es compatible con el desempeño en la clínica ampliada.

Palabras clave: terapia gestalt, cuidado, clínica ampliada.

O cuidado é uma das primeiras experiências que todo ser humano vivencia na sua chegada ao mundo. Desde o nascimento, somos carentes de cuidado e sem alguém que nos cuide, de fato pereceremos. O estado de fragilidade em que nascemos não diz respeito apenas a uma necessidade de cuidados físicos, mas também nascemos emocionalmente dependentes e, desde o início de nossas vidas, necessitamos receber alimentação e outros cuidados essenciais à nossa subsistência, como também atenção, proteção e afeto. Muitos autores consideram que a experiência de cuidado é de fato instaurada ainda em estágio uterino, pois sem uma genitora que zele minimamente pelo feto em desenvolvimento, há uma grande possibilidade de que o mesmo não chegue ao momento do nascimento e sucumba antes mesmo que esse ocorra. Contudo, nem sempre a falta de cuidados, ainda no período da gestação, implicará na morte do feto. Quando não houve o devido cuidado por parte da mãe ao longo da gestação, isto poderá trazer consequências posteriores ao desenvolvimento somático e emocional da criança (Keleman, 1992).

Alguns de nós vivemos uma condição privilegiada de termos sido "bem recebidos" já no início de nossas vidas. Desde o nascimento fomos bem cuidados, bem alimentados, acarinhados, amados e nascemos sem que o momento do parto tenha sido um momento de sofrimento, dor e privação. Em oposição a esta possibilidade, que é rara, muitos de nós nascemos em uma situação de sofrimento físico, sufocamento e desconforto ou, então, o momento do nosso nascimento não foi um momento de felicidade e realização para quem nos recebeu e, por conta disso, não fomos "bem recebidos" logo de imediato. As experiências iniciais de vida de muitos seres humanos são experiências de maus tratos, descuido, desconsideração e até mesmo de violência.

Um pouco mais tarde, quando a criança passa a receber ordens e ensinamentos por parte de quem as cuida, ela é introduzida na construção de um referencial de cuidados consigo mesma e com 
todos e tudo que a cerca, que chega por meio de ensinamentos transmitidos de vários modos, seja de forma mais doce e afetuosa, até de modo mais rude e ríspido. Recebendo uma série de comandos, tais como: "cuidado"; "assim não"; "isso machuca"; "isso me machuca"; "cuide de você"; "cuide dos seus objetos"; "seja cuidadosa com os outros". Tais comandos se estendem por muitos anos, até mesmo na vida adulta. Pois, mesmo adultos, recebemos alertas e recomendações do tipo: "não esqueça seu casaco, de noite pode fazer frio".

Ser cuidadoso e aprender a se cuidar são experiências que se correlacionam, sendo fundamentais para o desenvolvimento de uma "noção de si mesmo", para o entendimento de quem somos nós, e para a compreensão de nossas possibilidades e modos próprios de ser e estar no mundo. Tomaremos estas ideias, de modo introdutório, como premissas, tendo total consciência de que foram alvo de inúmeras reflexões e elaborações teóricas, não só por parte de estudiosos da psicologia, mas também de filósofos, educadores, além de outros profissionais e intelectuais. Mas penso que podemos nos arriscar a considerar, sem grandes elaborações a respeito, que ter sido cuidado (seja bem cuidado, malcuidado ou descuidado) é fundamental para a construção de uma noção de como se cuida de si mesmo e como se cuida do outro.

Neste artigo, pretendo definir o que consideramos cuidado e como o cuidado é pensado na Gestalt-terapia. A partir desta reflexão sobre o cuidado, irei discutir de que modo é possível estender essa visão sobre o cuidado para se pensar o que é cuidar dentro do modelo da clínica ampliada em Gestalt-terapia.

\section{O cuidado na Gestalt-terapia}

Para pensarmos a problemática trazida pelo tema deste artigo, gostaria de definir, inicialmente, o que iremos considerar como "cuidado". Quando pensamos em cuidado, nos referimos ao cuidado de alguém com outro alguém ou ao cuidado que dirigimos a nós mesmos? E o que é cuidar, afinal de contas?

O verbo cuidar deriva-se do termo latino cogitare (Michaellis, 2002). Cuidar, portanto, está diretamente relacionado à ideia de cogitar, ou seja, pensar, meditar e imaginar algo. O cuidado é então aquilo a que se dedica o pensamento, a imaginação, a atenção. Heidegger empregava o termo sorge (cuidado) no sentido das preocupações referentes ao futuro. Já o verbo sorgen (preocupar-se) o autor utilizava em dois sentidos: no sentido de se estar preocupado com algo, ou em relação a se tomar conta de alguém ou de algo (Inwood, 2002). O verbo sorge no tempo infinitivo (besorgen) tem o sentido de ocupar-se com algo, podendo assumir a forma de preocupação, ou 
seja, uma forma de cuidado ativo dirigido para outrem. Heidegger enfatizava que o cuidado (sorge) pertence ao próprio Dasein (ser-nomundo). Este modo de ser concebido como cuidado (Sorge) é um aspecto essencial de Dasein, é um modo próprio da sua existência (Inwood, 2002).

Foucault, na obra intitulada "La Hermeneutica del sujeto" (2002), trata da questão do cuidado do modo como era tratada na Grécia Antiga, mais especificamente por Sócrates. Foucault apresenta 0 conceito de epiméleia heautaû como equivalente da noção de cuidado consigo mesmo. Esta atitude, a epiméleia, é que dotaria o indivíduo de firmeza e clareza para tomar decisões acertadas quanto as suas atitudes em relação a si mesmo e também quanto aos assuntos do Estado. Segundo Foucault, este conceito do cuidado de si assemelhase a um processo meditativo, que não leva em consideração apenas os aspectos cognitivos, mas uma atitude de engrandecimento intelectual e espiritual, a partir deste voltar-se para si mesmo.

Percebemos, então, que tanto na visão de Heidegger (2002), quanto no conceito do cuidado de si mesmo apresentado por Foucault (2002), a ideia do cuidado compreende duas esferas - o cuidado consigo mesmo e o cuidado com o(s) outro(s). No entanto, para ambos os autores, estas duas esferas não são excludentes, muito pelo contrário. Heidegger (2002) fala de uma tríade inseparável - o cuidado (enquanto atitude própria ao ser-no-mundo), preocupação e ocupação. O Dasein, em seu modo de ser autêntico, é cuidado. O Dasein possui uma existência marcada pela historicidade, ou seja, ele tem um lugar no mundo, mundo este que está construindo e no qual sua atitude autêntica é a de cuidado. Já no conceito apresentado por Foucault (2002), esta atitude meditativa de voltar-se para si mesmo é uma busca de auto aperfeiçoamento para melhor compreender as necessidades dos outros, em busca de uma ação mais justa na sociedade.

$\mathrm{O}$ que podemos perceber em comum entre estes autores é a ideia de uma dupla direção no cuidado - o voltar-se para si e o voltar-se para o mundo, como inseparáveis.

E como se posiciona a Gestalt-terapia diante da conceituação de cuidado e levando-se em consideração o ponto de vista holístico, organísmico e da teoria de campo, que são pressupostos importantes desta abordagem? Partimos da noção de integração entre a pessoa (de quem se cuida) e o meio. Em Gestalt-terapia, pensamos o cuidado como um trinômio entre o afeto, o pensamento e a ação. Mais correto é: consideramos uma composição entre afeto, pensamento, ação e contextualização. Cuidado é mais do que um mero prestar atenção ou ter condutas em relação ao outro, mas é também vislumbrar este outro como uma faceta de um mosaico que envolve o campo afetivo, físico, social e cultural que compõe a realidade desta pessoa. 
$\mathrm{Na}$ Gestalt-terapia, encontramos a ideia de que durante o processo de desenvolvimento do ser humano vamos deixando de ser tão dependentes dos cuidados alheios $e$, ao longo do processo de maturação, vamos prescindindo da necessidade de apoio externo para a construção, cada vez maior, de um auto apoio. Segundo Perls (1977a, p. 49), "amadurecer é transcender ao apoio ambiental para o auto-apoio". Perls descrevia o processo de amadurecimento traçando um paralelo com a ideia de que amadurecer é estar "pronto para algo" (Perls, 1977a, p. 49) assim como as frutas e os animais. Na obra de Perls citada acima, ainda encontramos a definição da neurose "como um distúrbio do desenvolvimento" (Perls, 1977a, p. 49). Ou seja, Perls constrói a noção de que aprender a se cuidar é parte do processo de amadurecimento e que, quando isto não ocorre naturalmente, podemos pensar que há uma falha no processo de desenvolvimento, uma desordem de crescimento que ele nomeia de neurose.

Desse modo, podemos considerar que, do ponto de vista da Gestaltterapia, o processo de ser cuidado evolui para um aprendizado do autocuidado. Quanto mais se amadurece, menos a pessoa depende do cuidado alheio, pois cada vez mais é capaz de cuidar de si mesma e de construir referenciais próprios de suporte. Visto assim, o processo de amadurecimento é um processo de construção de autonomia e de libertação de relações de extrema dependência. $O$ contrário a isso é o que Perls chamou de neurose (1977a). Do mesmo modo, quando Perls descreve os mecanismos neuróticos (1977a), ele define a introjeção como sendo o "mecanismo neurótico pelo qual incorporamos em nós mesmos, normas, atitudes, modos de agir e pensar, que não são verdadeiramente nossos." (1977a, p. 48). Ou seja, o "neurótico" não só não é capaz de construir um auto apoio suficiente, como também não desenvolve adequadamente ideias, normas e atitudes próprias.

Segundo Perls (1977a, p. 45), "o neurótico é um homem sobre quem a sociedade influi demasiadamente". Autonomia, capacidade de reflexão e criatividade são atitudes próprias ao desenvolvimento saudável do ser humano. Em oposição a isto, dependência excessiva, repetição de ideias, normas e atitudes são características neuróticas do indivíduo. Todavia, se considerarmos estes princípios defendidos pela Gestalt-terapia de modo mais amplo, assim como o próprio Perls o fez (1977a, 1977b), uma sociedade composta por muitas pessoas neuróticas é uma sociedade neurótica, e em uma sociedade neurótica a neurose passa a ser um padrão de funcionamento aprendido e perpetuado por aqueles que a compõem. Pensando deste modo, nas sociedades neuróticas não há o desenvolvimento adequado de relações de autonomia e de reflexão sobre os valores e normas adotadas. 
Podemos transitar dentro dos conceitos diagnósticos da Gestaltterapia, do que se considera neurose individual, para a elaboração de conceitos diagnósticos sociais. Na visão da "neurose social", entendese que nas sociedades neuróticas há a perda da autonomia na autogestão. Um dos principais sinais de bloqueio no desenvolvimento das comunidades, grupos e sociedades é a perda da autonomia e da possibilidade de construção de ideias e valores próprios. Se considerarmos que uma das principais funções da clínica gestáltica é a da valorização da busca da autonomia, e que para isso a construção da capacidade do sujeito de cuidar de si mesmo é fundamental, do mesmo modo, no trabalho da clínica ampliada há um objetivo claro de se incentivar, nas comunidades e grupos sociais, a busca de recursos e soluções próprias para o seu desenvolvimento autônomo.

Voltando ao início deste texto, construí a ideia de que, no processo de desenvolvimento da criança, ser cuidada é essencial na construção posterior da possibilidade de cuidar de si mesma. O modo como fomos cuidados em nossas vidas se refletirá no adulto que seremos, de muitas formas. Pensando do ponto de vista social, o que podemos considerar como cuidados sociais essenciais para o desenvolvimento dos grupos sociais e comunidades? Consideração aos direitos sociais, valorização das necessidades próprias a cada grupo ou comunidade, respeito às diferenças individuais e coletivas, penso ser princípios básicos para um desenvolvimento social "não neurótico".

Segundo Perls (1977a), referindo-se ao neurótico, "O objetivo da terapia, então, deve ser lhe dar meios, para que possa resolver seus problemas atuais e qualquer outro problema que surja amanhã ou no próximo ano. Este instrumento é a auto-estima." (p. 75). E na clínica ampliada? Qual o trabalho que a Gestalt-terapia se propõe a desenvolver com as comunidades e grupos com os quais atua? Partindo da afirmação de Perls transcrita acima, é tarefa da clínica ampliada fornecer meios próprios para que aquela comunidade possa lidar com seus problemas atuais ou quaisquer outros problemas futuros que surjam.

Neste texto, me dedicarei a refletir um pouco e repensar a prática de estágio supervisionado em Gestalt-terapia que coordeno há alguns anos em uma universidade federal, mais especificamente, no curso de psicologia da UFF de Rio das Ostras, prática esta que se desenvolve em atendimento clínico e ações na clínica ampliada. Esta prática vem sendo desenvolvida em parceria com a Prefeitura de Rio das Ostras e está vinculada ao trabalho que ocorre em dispositivos da rede de saúde e de assistência social, realizado por psicólogos. Através dessa parceria, venho acompanhando atividades desenvolvidas por estagiários sob minha supervisão e orientação conjunta dos psicólogos da rede, em diferentes locais. Já pudemos estar em diversos projetos e instituições, tais como: o Abrigo Municipal de Rio das Ostras; o Hospital Geral de Rio das Ostras; o 
projeto de acompanhamento de pacientes - DST/HIV; o Ambulatório de Saúde Mental de Rio das Ostras; o Projeto Canguru de acompanhamento de gestantes pela equipe da Secretaria do Bem Estar Social; a Creche Social que atende crianças em situação de alta vulnerabilidade; o acompanhamento ambulatorial em posto de saúde das gestantes de alto risco; o acompanhamento dos adolescentes, também em situação de vulnerabilidade no Centro Integrado de Convivência da Prefeitura; e alguns outros locais onde pudemos garantir, através da oferta de estágio, que mais pessoas pudessem receber algum tipo de assistência psicológica em situações de sofrimento nos dispositivos do município, que são carentes de profissionais em número suficiente para a demanda da população atendida. Também desenvolvemos um trabalho com o atendimento individual e grupal no Serviço de Psicologia Aplicada da Universidade de acompanhamento psicoterápico à comunidade do município em regime de clínica social, comunidade essa bastante desassistida e sofrida, dada à situação de vulnerabilidade social em que vive grande parte da população da cidade e a precariedade dos serviços de atendimento médico e psicológico da rede do município.

\section{De como fomos à luta e entramos em campo}

"Vem, vamos embora, que esperar não é saber. Quem sabe faz a hora, não espera acontecer." (Geraldo Vandré, 1979).

E foi assim que chegamos à rede de Rio das Ostras, através da uma proposta de cooperação e parceria entre o Serviço de Psicologia da universidade com os profissionais das Secretarias de Assistência Social e de Saúde do município. Chegamos não sabendo o que iríamos fazer, mas acreditando que precisávamos fazer alguma coisa acontecer. Fomos à luta e entramos em campo, sem ideias prévias do que encontraríamos e de qual tipo de trabalho que seria possível desenvolver.

Qual prática poderia ser desenvolvida por estagiários no Hospital Geral, no Abrigo Municipal, na rede de Saúde Mental e em outros dispositivos? O que guiaria o trabalho desenvolvido pelos alunos em dispositivos tão diferenciados, e onde as ações que se desenvolveriam seriam de grande especificidade, em relação à demanda dos serviços? Eram perguntas sem respostas, naquele momento, mas nos dispomos a correr o risco de entrar em campo, mesmo sem termos certezas do trabalho que seria possível ser desenvolvido, por acreditarmos que esta experiência seria frutífera para nós, professores e alunos, enquanto material de pesquisa e aprendizado. Assim como para os usuários da rede, totalmente 
desguarnecida e carente de serviços que dessem conta das demandas de urgência e sofrimento em grau extremo.

Importante destacar que os psicólogos dos campos, onde esses alunos foram e são recebidos, não atuam como gestalt-terapeutas, na sua maioria. Apenas em uma situação, pudemos compartilhar a experiência com uma psicóloga cuja abordagem era a da Gestaltterapia atuando no Abrigo Municipal de Rio das Ostras. No entanto, a orientação dada por mim, enquanto supervisora de estágio, sempre foi dentro dos pressupostos clínicos da abordagem gestáltica. Isto nunca foi empecilho ou problema na atuação destes alunos, pelo contrário. A relação que estabelecemos com os psicólogos do campo tem sido de imensa confiança, respeito, admiração e parceria. Com isso, buscamos promover muitos encontros e trocas entres os profissionais que atuamos, momentos muito nutritivos e de imensa colaboração mútua.

A prática desenvolvida por esses estagiários inspirou mais de 15 monografias de Final de Curso, todas elas ancoradas teoricamente na Gestalt-terapia e nas vivências dos alunos no campo, construídas a partir da experiência que viveram nos dispositivos que atuaram. Para escrever este artigo, busquei reler as introduções destas monografias e me emocionei muitíssimo em me deparar com a riqueza e a profundidade de reflexão e contribuição para a prática da Gestaltterapia na clínica ampliada que estes trabalhos produziram. Fico agradecida pela oportunidade que tive de ter recebido ex-alunos e estagiários tão maravilhosamente "gestálticos". De modo semelhante, tenho gratidão pelo fenômeno que se deu no "campo", onde encontramos na rede profissionais íntegros, comprometidos, disponíveis e éticos em seus modos de ser psicólogo e de estar com os usuários.

Voltando ao que discutimos até aqui sobre a noção de cuidado em Gestalt-terapia, passo a refletir sobre o modo como exercemos a função de cuidar nas atuações de atendimento, dentro do ponto de vista da clínica ampliada. O que é isso que nos propomos a fazer quando estamos diante do outro, seja este outro um adulto, uma criança, uma família, um determinado grupo social ou uma comunidade específica? Me lembro agora da belíssima música de Milton Nascimento (2014) na qual ele diz que "Todo artista tem de ir aonde o povo está". Onde e como será que o povo se encontra neste momento sócio cultural e político que atravessamos? Com certeza grande parte da população brasileira vive hoje situações em que necessita de cuidado, buscando este cuidado junto à rede pública de saúde, de assistência social e de educação. Se nós, como artistas do nosso trabalho, queremos estar aonde o povo está, precisamos exercer nosso ofício em contato direto com essa população que se encontra em estado de "des-assistência". Quase a totalidade da população brasileira precisa contar com a rede pública de saúde e de 
educação para buscar ser assistida naquilo que todo e qualquer ser humano merece ter garantido de modo irremediável: acesso à educação, à saúde e aos programas sociais que lhe garantam uma vida com o mínimo de dignidade.

Quando saímos de uma proposta da atuação clínica que move seu enquadre para além do modelo das quatro paredes do consultório e se reorienta para um modo de escuta e acolhimento que acontece onde "o povo está" - nos mais variados contextos - podemos considerar esta proposta de trabalho como clínica ampliada.

Segundo Cambuy e Amatuzzi (2012), no trabalho do psicólogo em clínica ampliada, é importante também "se ampliar a noção de que ser psicólogo representa muito mais do que oferecer atendimentos individualizados, centrados em queixas psicológicas específicas." ( $p$. 675). A escuta profissional, no enquadre da clínica ampliada, busca a valorização do ser humano, sempre considerando as imbricações socioculturais do seu discurso. O fazer clínico neste contexto "não significa apenas lidar com a interioridade psicológica do sujeito, mas também com toda a rede de subjetividade que o envolve." (Cambuy \& Amatuzzi, 2012, p. 675).

Dimenstein (2000) refletindo sobre o impacto ocorrido com a entrada dos profissionais de psicologia no campo da assistência pública à saúde no Brasil, considerou que: "O modelo clínico de atuação privada hegemônico entre os psicólogos - a psicoterapia individual de base analítica - é geralmente transposto para o setor público." ( $p$. 107). Destacando inúmeros conflitos que ocorreram e trouxeram consequências importantes, mas que, segundo a autora, em grande parte derivavam "da predominância no campo da Psicologia de enfoques em que o indivíduo é tratado como um ser a-histórico, desvinculado de seu contexto social." (Dimenstein, 2000, p. 108).

Perls (1977a) definia a abordagem gestáltica como aquela "que considera o indivíduo uma função do campo organismo/meio. . . . dá coerência à concepção do homem tanto como indivíduo quanto ser social." (p. 39). A Gestalt-terapia adota a visão de homem em permanente interação com o contexto sócio-político-cultural e ambiental que o envolve. Também é importante destacar que o trabalho com grupos em Gestalt-terapia sempre foi bastante valorizado. Grande parte dos profissionais que adotam essa abordagem na rede de saúde pública já possuem, a partir da sua formação, afinidade com o trabalho em grupos. Deste modo, é possível pensar que os pressupostos teóricos e técnicos da Gestaltterapia favorecem a atuação no contexto da clínica ampliada.

A prática da clínica ampliada em Gestalt-terapia se dirige para o trabalho com a valorização dos grupos e comunidades com as quais atua, buscando resgatar potenciais de realização e superação coletivos. Desejamos que estes "re-conheçam" o que podem fazer por si mesmos, usando recursos próprios e desenvolvendo 
habilidades e talentos, muitas vezes esquecidos e perdidos, mas que tenham em si força e potência de gerar conscientização, criar alternativas antes não percebidas e/ou valorizadas, possibilitando ações efetivas de transformação da realidade de múltiplas restrições e impotência. Entendemos que isso é cuidado - deixar que o(s) outro(s) encontre(m) sua(s) própria(s) resposta(s), coerente(s) com quem é(são) e com suas crenças. Nossa tarefa é ajudá-los a acreditar que são capazes de cuidar de si e de todos ao seu redor, da melhor forma possível, em cada situação.

Estes princípios vão ao encontro da crença na autorregulação organísmica e de que fazer ajustamentos criativos é imprescindível para se buscar encerrar situações inacabadas, além de revolucionar e transformar realidades, mesmo diante de todos os empecilhos e impedimentos impostos pelo meio. Voltando à visão de neurose trazida por Perls, o trabalho em clínica ampliada é um trabalho voltado à valorização das possibilidades criativas e inovadoras de cada um em inventar respostas e encontrar caminhos possíveis de transformação da realidade em que se encontra. Lembrando que autonomia se refere a um movimento próprio e, de modo algum, significa estagnação e adaptação, mas mudança e transformação. Isso não significa tentar "minimizar" o sofrimento, a revolta e a indignação do outro.

Tenho a premissa, que compartilho com todos os meus estagiários, de que acolher alguém é um privilégio. Que humildemente temos que agradecer pela beleza que existe em estar com um outro ser humano e este nos oferecer a oportunidade de se revelar, naquilo de mais humano que traz em si, a vulnerabilidade diante da vida. Somos todos seres lançados no mundo, alguns de modo mais suave, outros arremessados com mais violência - mas todos vivemos a condição de que temos uma vida a ser vivida, não se sabe até quando e em que condições, pois estamos absolutamente entregues ao mistério do que virá a ser de nós. Diante dessa premissa, que conduz minha trilha profissional e pela qual convido outros a caminharem comigo, paro para refletir: afinal, o que é isso que guia a postura do gestaltterapeuta - seja exercida junto a crianças em situação de abrigamento, pessoas hospitalizadas em diversas circunstâncias, mulheres vítimas de violência doméstica, ou seja lá em que solo ou campo formos aceitos e convidados a transitar? Destacando aqui que, toda vez que me referir ao outro, poderei estar me referindo a pessoas individualmente, assim como a grupos, a comunidades e a membros de uma determinada instituição, sem distinção alguma de gênero ou posição social.

A proposta da Gestalt-terapia não é a de oferecer respostas e/ou promessas de resolução para as dificuldades, bloqueios e impossibilidades que são vivenciadas pelas pessoas que nos deparamos quando vamos ao campo. Não pretendemos dar conselhos 
ou fazer pelo outro. Mas nos dispomos, verdadeiramente, a estar com - dentro do que Buber (2012) descreve como encontro, ao longo de sua obra, e que ancora os pressupostos dialógicos da nossa abordagem. Nossa busca é de compreensão e não de explicação ou julgamento. Me inspirando nas palavras de Rogers (1982, p. 55): "Para mim, o indivíduo que fala é importante, merece compreensão; consequentemente, ele é importante por ter exprimido qualquer coisa".

O modo que escolhemos estar com o outro, que é teoricamente e filosoficamente apoiado nos princípios da nossa abordagem, se orienta por uma postura de profundo respeito, consideração e solidariedade. Como escreveu o colega Jorge Ponciano Ribeiro (1994), devemos nos colocar humildemente diante do outro, de modo a respeitá-lo em sua sabedoria e experiência de vida.

Diante do outro, somos pessoas nos relacionando com pessoas, seres humanos que se encontram. Isto significa que nos impactamos, emocionamos, nos sentimos muitas vezes tocados, condoídos (ou com doídos) com aquilo que o outro nos revela, seja através de palavras, ou através da possibilidade de testemunhar suas marcas corporais e de nos defrontarmos com a observação das condições de vida que este outro experimenta. Lembrando que aquilo que testemunhamos merece consideração e sigilo, dentro do que o outro nos autoriza a revelar e partilhar em relação a sua própria vida.

Partindo de um trecho de música de Gilberto Gil (1982) em que ele diz: "Andar com fé eu vou que a fé não costuma faiá", conduzimos o trabalho em clínica ampliada sempre ancorados em uma postura de muita fé. Acreditamos no potencial criativo do ser humano de se reinventar e buscar respostas novas, mesmo nas condições mais adversas. A autorregulação é compreendida como potencial do ser humano em buscar sempre a melhor possibilidade de lidar com cada situação, encarando as frustrações e impedimentos impostos pelo meio e criando modos alternativos comunitários de resolver os impasses, conseguindo alcançar a melhor forma possível de se chegar a uma boa resolução para as demandas que surgem.

É importante destacar que a fé na autorregulação não basta. Que é parte do nosso trabalho transmitir essa fé ao outro e tentar, junto com este, reconhecer quais os recursos e valores do seu grupo que podem ser ativados em cada situação, e de que modo essa comunidade pode se unir em uma grande rede de colaboração e ajuda mútua. Como cada um pode contribuir, do seu modo, disponibilizando ao grupo depoimentos sobre soluções que tem encontrado, construindo, assim, parcerias de ajuda mútua entre todos os envolvidos na situação. É imprescindível que os grupos comunitários possam reconhecer suas principais demandas e as alternativas possíveis de ação, em cada situação, levando em consideração quais os recursos próprios que podem disponibilizar 
através de ações conjuntas. Esse exercício de construção de ações, que visam à autonomia dos grupos na resolução de suas principais demandas e necessidades, é o foco do nosso trabalho e o que nos guia.

Parte da nossa função, como psicólogos atuando na clínica ampliada, é trabalhar buscando promover uma maior conscientização das necessidades, bem como das demandas individuais e sociais daqueles que atuamos, além dos recursos e conhecimentos próprios que podem ser ativados em busca de soluções conjuntas. Podemos, através do nosso exercício profissional, facilitar no que for possível o acesso a respostas dos envolvidos na situação, meios e atalhos para chegarem ao que podem conseguir obter de modo autônomo e responsável. Para isso, precisamos trabalhar associados com toda a rede que está ao redor daquela situação específica. Em se tratando do hospital, por exemplo, podemos atuar no contato direto com as psicólogas que lá trabalham, promovendo reuniões, encontros e se dispondo a participar, junto com os estagiários, de projetos que visem a melhoria dos serviços que ocorrem no hospital e que impactam, diretamente, na experiência emocional dos que ali se encontram em atendimento.

A grande maioria das ações dos psicólogos que atuam na clínica ampliada são ações de equipe, nas quais o psicólogo atua juntamente com outros profissionais e diretamente vinculado aos membros da comunidade envolvidos na situação. Precisamos entrar na rede, até para colaborarmos na identificação dos furos, rupturas e descontinuidades que se dão nela. Não olhamos de fora e julgamos, mas no encontro com o outro nos colocamos de modo a sentir os impactos e rupturas, buscando identificar as demandas e precariedades da situação.

Esta prática pode ser compreendida como uma prática colaborativa (Silva, Peduzzi, Orchard, \& Leonello, 2015), pela qual o "usuário é reconhecido como um sujeito autêntico que possui identidade e participa como um agente de transformação da sua história individual e coletiva, ou da sua saúde." (p. 21).

Desse modo, dentro da visão da abordagem gestáltica, nossa ação não se guia pelo viés assistencialista. Não fazemos pelo outro, mas nos dispomos a estar com o outro buscando vislumbrar novos modos do seu próprio fazer. A função do trabalho da clínica ampliada é, portanto, facilitar que o "usuário" encontre modos próprios e autônomos de resolução das suas dificuldades diante das restrições em sua existência.

A nossa orientação de trabalho na clínica ampliada é sempre ancorada na visão de homem e de mundo da abordagem. Sendo assim, este homem com quem nos relacionamos é visto como ser-nomundo, sujeito cuja "existência precede a essência" (Sartre, 2015, p. 15), segundo pressupostos fenomenológicos e existenciais. Para 
sermos alguém, precisamos existir, e para possibilitarmos que todos os que estão ao nosso redor possam ser alguém, temos o compromisso ético e social de denunciarmos condições que não thes assegurem a existência de forma humanamente digna e autônoma.

\section{Considerações Finais}

Penso que seja interessante para terminar uma situação, lembrar de como foi o seu início. Neste sentido, volto ao início desse artigo onde escrevi que aprender a se cuidar é parte fundamental do desenvolvimento da noção de si mesmo e que a forma como fomos cuidados, desde o início das nossas vidas, se reflete e se atualiza na maneira como passamos a cuidar de nós mesmos. Também é importante considerarmos os princípios da abordagem gestáltica, que nos dão uma direção do que é cuidar em Gestalt-terapia. A compreensão do cuidado que adotamos é orientada por princípios fenomenológicos, organísmicos, de campo e holísticos. A postura que adotamos diante do outro que se apresenta a nós, seja esse outro uma pessoa, um grupo ou uma comunidade específica, é dialógica, onde nos colocamos de modo respeitoso, sendo imprescindível respeitar e incentivar a autonomia e o modo próprio de existência de cada ser humano que vem ao nosso encontro.

A Gestalt-terapia nasceu como uma proposta psicoterápica de atendimento individual, mas rapidamente foi adotada no trabalho com grupos em diversos contextos. No final da vida, Perls criou uma comunidade baseada em princípios gestálticos e sempre defendeu que a Gestalt-terapia não era apenas uma abordagem de psicoterapia, mas sim uma postura de vida. Sabemos pouco sobre essa experiência de Perls de uma vida em comunidade em moldes gestálticos, pois ele faleceu logo a seguir. Ao que tudo indica, ele viveu momentos de realização e felicidade não apenas "trabalhando" como um gestalt-terapeuta, como também vivendo gestalticamente.

A Gestalt-terapia, de fato, se expandiu de uma prática clínica individual para a psicoterapia de grupo, para o trabalho com grupos no ambiente institucional, para ações comunitárias, além de ser adotada por profissionais em todo o mundo, muito além dos consultórios de psicoterapia. Esta expansão de possibilidades na atuação dos gestalt-terapeutas não é mero acaso. A abordagem gestáltica é muito bem recebida e bastante adequada ao trabalho da clínica ampliada. A pluralidade de formas de intervenção e instrumentais técnicos de que se utilizam o gestalt-terapeuta, possibilitou a adequação de sua atuação em comunidades e grupos diversos. Sabe-se de gestalt-terapeutas que trabalham com recursos artísticos e materiais muito diferentes, como a música, o teatro, a argila, entre outros. 
O gestalt-terapeuta tem a liberdade de criar modos de atuação e ser criativo naquilo que faz, desde que não abandone a visão de cuidado que o orienta. Cuidar gestalticamente é incentivar a autonomia, respeitar todo e qualquer ser humano no seu modo de ser e estar diante do outro humildemente, pois somos todos seres-no-mundo, atravessados pela existência mundana onde somos cuidados e cuidadores.

Precisamos, cada vez mais, aprender a cuidar melhor de tudo que nos rodeia. Cuidar de nós mesmos, cuidar daqueles que nos cercam, cuidar do nosso planeta, já que seguindo o que dizia Renato Russo (1987): "Tem gente que machuca os outros, tem gente que não sabe amar, tem gente enganando a gente. Veja a nossa vida como está".

Segundo Cardella (1994) a confiança é parte fundamental da relação que se estabelece entre o gestalt-terapeuta e aquele com quem se relaciona profissionalmente, pois confiar "não pressupõe apenas conhecimentos teóricos e técnicos mas, antes de tudo, confiança na humanidade, na possibilidade de relações mais verdadeiras, no possível bem estar do homem, na harmonia e no amor." (p. 64).

É confiando no(s) outro(s) que exercemos o cuidado. Cuidado que perpassa a prática profissional do gestalt-terapeuta, se revelando na atitude amorosa e respeitosa que assumimos diante daqueles que nos propomos a estar. O nosso modo de cuidar pode se dar por uma escuta atenta e silenciosa, mas também quando cuidamos, podemos chorar junto com o outro. Devemos legitimar sua dor e mostrar o quanto as suas experiências nos tocam. Admitir que a realidade que o outro vive muitas vezes nos revolta. Não podemos "carregar suas bandeiras", contudo, podemos andar ao seu lado, de mãos dadas. Dar as mãos e caminhar juntos pode ser um modo de cuidar. Saber a hora de soltar as mãos e permitir que o outro siga seu caminho, também é cuidar.

Na Gestalt-terapia não existe uma "receita" de cuidado. Aprendemos com o(s) outro(s) e em cada momento o modo próprio e singular de estar com, em cada situação, contexto e ambiente.

\section{Referências}

Buber, M. (2012). Eu e Tu. São Paulo, SP: Centauro Editora.

Cambuy, K., \& Amatuzzi, M. M. (2012). Experiências comunitárias: repensando a clínica psicológica no SUS. Psicologia e Sociedade, 24(3), 674-683. Doi: 10.1590/S010271822012000300020

Cardella, B. (1994). O amor na relação terapêutica - Uma visão gestáltica. São Paulo, SP: Summus.

Dimenstein, M. (2000). A cultura profissional do psicólogo e o ideário individualista: implicações para a prática no campo da 
assistência pública à saúde. Estudos de Psicologia, 5(1), 95121. doi: $10.1590 / S 1413-294 X 2000000100006$

Foucault, M. (2002). La Hermeneutica del sujeto. Mexico: Fondo de Cultura Economica.

Geraldo Vandré. (1979). Caminhando. Pra não dizer que não falei das flores. São Paulo, SP: RGE Discos.

Gilberto Gil. (1982). Andar com fé. Um Banda Um. Rio de Janeiro, RJ: WEA Records.

Heidegger, M. (2002). Ser e tempo - Parte 1. Petrópolis, RJ: Editora Vozes.

Inwood, M. (2002). Dicionário Heidegger. Rio de Janeiro, RJ: Jorge Zahar Editor.

Keleman, S. (1992). Anatomia emocional. São Paulo, SP: Summus.

Michaellis. (2002). Dicionário da Língua Portuguesa. São Paulo, SP: Melhoramentos.

Milton Nascimento. (2014). Nos bailes da vida. Aos amigos. Rio de Janeiro, RJ: Universal Music.

Perls, F. (1977a). A abordagem gestáltica e testemunha ocular da terapia. Rio de Janeiro, RJ: Zahar Editores.

Perls, F. (1977b). Gestalt-Terapia Explicada. São Paulo, SP: Summus.

Renato Russo. (1987). Mais uma vez. Presente. Rio de Janeiro, RJ: EMI.

Ribeiro, J. (1994). Gestalt-Terapia - o processo grupal. São Paulo, SP: Summus.

Rogers, C. (1982). Grupos de encontro. Rio de Janeiro, RJ: Martins Fontes.

Sartre, J. P. (2015). O que é a subjetividade? Rio de Janeiro, RJ: Nova Fronteira.

Silva, J. A. M., Peduzzi, M., Orchard, C., \& Leonello, V. M. (2015). Educação interprofissional e prática colaborativa na Atenção Primária à Saúde. Revista da Escola de Enfermagem da USP, 49(2), 16-24. Doi: 10.1590/S0080-623420150000800003

\section{Endereço para correspondência}

Patricia Valle de Albuquerque Lima

Rua Eduardo Guinle, 60 apto 602, Botafogo, CEP 22260-090, Rio de Janeiro - RJ, Brasil

Endereço eletrônico: ticha.patricia@globo.com

Recebido em: 10/10/2019

Reformulado em: 31/01/2020

Aceito em: $12 / 02 / 2020$

\section{Notas}

* Doutora em Psicologia, Professora Associada do Departamento de Psicologia da UFF/ Rio das Ostras, Supervisora de Estágio em Gestalt-terapia, membro da Associação Brasileira de Gestalt-terapia (ABG). 
Patricia Valle de Albuquerque Lima

Este artigo de revista Estudos e Pesquisas em Psicologia é licenciado sob uma Licença Creative Commons Atribuição-Não Comercial 3.0 Não Adaptada. 